\title{
The Effect of High Schoolers' Callous-Unemotional Traits and Narcissism on Aggression
}

\author{
Sae-Young $\mathrm{Han}^{1}$, Yeon Soo $\mathrm{Cho}^{2}$ \\ Professor, Department of Child Development, Ewha Womans University, Seoul, Korea ${ }^{1}$ \\ Ph. D. Student, Department of Child Development, Ewha Womans University, Seoul, Korea ${ }^{2}$ \\ 고등학생의 냉담-무정서와 자기애가 공격성에 미치는 영향 \\ 한세영 ${ }^{1}$, 조연수 ${ }^{2}$ \\ 이화여자대학교 아동학과 교수 ${ }^{1}$, 이화여자대학교 아동학과 박사과정 ${ }^{2}$
}

Objectives: The study aimed to investigate the main and interaction effects of callous-unemotional traits and narcissism on Korean high schoolers' aggression.

Methods: The participants were 315 high school students (155 boys, 160 girls) in South Korea. To measure the level of high schoolers' callous-unemotional traits, the 'Korean Inventory of Callousunemotional traits' was used. Narcissism and aggression were measured via the 'Narcissistic Personality Disorder Scale' and 'Buss-Durkee Hostility Inventory', respectively. The data were analyzed by means of descriptive analysis, Pearson's correlation analysis, multiple regression analysis and hierarchical multiple regression analysis via SPSS 21.0

Results: First, there were significant correlations among high schoolers' callous-unemotional traits, aggression, and narcissism. Second, high schoolers' callous-unemotional traits and narcissism affected aggression partially. Specifically, 'callousness' and 'egocentrism' had positive effects on aggression while 'unemotional' traits had a negative effect on aggression. Third, the interaction effects of high schoolers' callous-unemotional traits and narcissism on aggression were partially significant. Specifically, the interaction effects of 'callousness' and 'egocentrism' as well as 'uncaring' and 'egocentrism' were significant. That is, the effects of 'callousness' and 'uncaring' on aggression were greater when 'egocentrism' was low, compared to when it was high.

Conclusion: The results indicate the need for a granular approach to understanding high schoolers' aggression and to develop counseling programs based on the role of high schoolers' callousunemotional traits and narcissism in aggression.

Keywords: high schoolers, adolescence, callous-unemotional traits, narcissism, aggression

\section{Introduction}

최근 한국사회는 소년법 개정에 대한 사회적 논의가 활발하 게 이루어지고 있다. 그 주된 이유는 가해 청소년에 대한 처벌 수위에 비해 청소년 범죄의 잔혹함이 날로 심각해지고 있기 때문이다. 최근 통계청에서 발표한 '2019 청소년통계(Statistics

Corresponding Author: Yeon Soo Cho, Ph. D. Student, Department of Child Development, Ewha Womans University, 52, Ewhayeodae-gil, Seodaemungu, Seoul, Korea

E-mail: yeons00401@gmail.com
Korea, 2019)'에 따르면, 청소년범죄 중 살인, 강도, 방화, 성폭 력 등과 같은 강력범죄의 비중이 2008 년 $27.4 \%$ 이었던 것에 반 해 2017년에는 33.7\%로 약 5\%가 증가했다. 이러한 실태는 우 리나라 청소년의 공격성이 날로 심각해지고 있음을 보여준다.

공격성은 공격적인 행동뿐 아니라, 분노감, 적대감과 같은 공격적 정서 및 공격적 인식을 모두 포함하는 개념을 말한다

(C)The Korean Association of Child Studies

This is an Open Access article distributed under the terms of the Creative Commons Attribution Non-Commercial License (http:// creativecommons.org/licenses/by-nc/4.0) which permits unrestricted noncommercial use, distribution, and reproduction in any medium, provided the original work is properly cited. 
(Buss \& Perry, 1992). 특히 청소년기는 정서적으로 성충동의 급격한 증가로 정서적 혼동을 경험하며, 이는 불안감과 과민 성을 증대시켜(S. C. Han, 2012), 이러한 정서적 불안감이나 긴 장감을 해소하기 위해 공격성이 증가하는 시기이다. 공격성 을 예측하는 변인은 크게 개인 외적 변인과 내적 변인으로 나 누어 볼 수 있는데, 바람직하지 못한 양육행동, 또래관계 등과 같은 외적 변인에 대한 연구(Espelage, Holt, \& Henkel, 2003; Kawabata, Alink, Tseng, Van Ijzendoorn, \& Crick, 2011) 외에도 개인의 심리, 정서적 측면과 같은 개인 내적 변인에 대한 접근 이 이루어져 왔다.

먼저 공격적 성향이 높은 청소년인 경우 정서적 특징으로 낮은 공감능력이 지속적으로 보고되어 왔다. 그러나 최근 청 소년의 공격행동의 심각한 수준에 비추어 단순히 낮은 공감능 력 이상의 정서적 특징으로, 냉담-무정서 특질이 논의되기 시 작하였다. 상대방의 감정에 감응하지 못하는 낮은 공감능력을 너머, 평소의 감정상태의 이상을 나타내는 냉담-무정서의 특 질이 강한 경우에 공격적 성향을 띠게 된다는 것이다. 냉담-무 정서 특질은 성격특성의 하나로, 아동기에 시작하여 청소년기 와 성인기까지 유지되어 반사회적 행동과 품행장애의 하위유 형으로 나타내게 된다(Frick \& Dickens, 2006; Frick \& White, 2008). 냉담-무정서 특질 척도는 정신병질을 평가하기 위한 도구인 the Psychopathy Checklist (PCL; Hare, 1991)를 시작으 로, 청소년기 이전의 아동을 대상으로 4 개 요인(대인관계, 정 서성, 생활양식, 반사회성)을 검사하기 위한 도구인 Antisocial Process Screening Device (APSD; Frick \& Hare, 2001)가 개발되 었으나, 두 검사 모두 냉담-무정서 특질에 대한 평가가 부분 적으로 이루어졌기 때문에(Lee \& Lee, 2016), 최근에는 이를 보완한 Frick (2003)의 Inventory of Callous-Unemotional Traits (ICU)가 널리 사용되고 있다. Frick (2003)은 냉담-무정서의 구 성요소로 냉담성(callousness), 부주의/무신경(uncaring), 무정서 (unemotional) 등과 같은 세 가지 영역을 제안하였다. 냉담성은 공감, 후회, 죄책감의 결여와 관계가 있으며, 부주의/무신경은 학교과제나 대인관계과제와 같은 과제수행에 대한 관심이 적 은 것, 무정서는 정서성의 부족을 의미한다.

냉담-무정서(Callous-Unemotional) 특질은 심각할 경우 사 이코패스 집단의 특징으로 지목되기도 하고, 품행장애 청소 년 또는 비행청소년들의 특징으로 조사된 바도 있다(Lee \& Lee, 2016; Song \& Lee, 2014). DSM-5 (American Psychiatric Association, 2013)에 의하면, 냉담-무정서 특질은 '친사회적 정서의 제한'으로 설명되며 품행장애의 진단적 지표로 설명 된다. 이러한 냉담-무정서 수준이 높은 아동은 품행장애와
도 상관이 있는데(Frick \& Viding, 2009), 만성적이고 심각한 품행장애 궤적을 보이기도 한다(Asscher et al., 2011; Dadds, Fraser, Frost, \& Hawes, 2005; Frick, Stickle, Dandreaux, Farrell, \& Kimonis, 2005; Kimonis, Kennealy, \& Goulter, 2016). 그러나 품 행장애 청소년과 일반 청소년의 냉담-무정서 특질은 차이가 없었으며, 품행장애 청소년의 경우 냉담-무정서 특질의 하위 영역인 '무관심', '냉담', '무정서' 중 무정서만이 일반 청소년보 다 유의미하게 높았다는 연구결과 역시 존재한다(Lee \& Lee, 2016).

이러한 결과는 일반 청소년도 냉담-무정서의 특질을 가지 되, 하위요인별로 그 분포 양상이 다르다는 점을 알려주었고, 품행장애 진단의 결과를 바탕으로 일반청소년의 행동을 예측 하고 일반화하기에는 무리가 있어, 품행장애 진단을 받은 청 소년 뿐 아니라 일반 청소년들의 공격성과 냉담-무정서의 각 하위요인 간의 관계에 대해 심층적으로 연구할 필요성이 있음 을 시사한다. 그러나 아직까지 비행 청소년이나 품행장애 청 소년, 사이코패스 집단을 제외한 일반 청소년들을 대상으로 냉담-무정서와 공격성의 관계를 살펴본 연구는 국내에서 많 지 않은 편이다. 최근에는 냉담-무정서와 중학생의 사이버 가 해행동 간에 유의한 상관이 있음을 밝혀(Shim \& Lee, 2018), 청소년의 공격성의 바탕에는 정서적으로 냉담한 특징이 있을 수 있음을 증명한 바 있다. 국외에서는 냉담-무정서의 특질이 강한 경우 주도적 공격성과 반응적 공격성이 모두 높아진다는 보고가 있었다(Barry, McDougall, Anderson, \& Bindon, 2018). Wright, Harper와 Wachs (2019)의 연구에서는 청소년들이 오프 라인의 면대면 괴롭힘행동, 익명이나 기명의 사이버괴롭힘행 동 모두에 대해 냉담-무정서 중 냉담성과 부주의/무신경이 정 적 영향을 미쳤다고 보고하여 다양한 유형의 괴롭힘이나 공격 적 성향에 상관이 있음을 알 수 있다. 그러나 같은 연구에서도 냉담-무정서의 하위요인인 무정서(unemotional)는 괴롭힘 행 동과 유의한 상관을 보이지 않아, 공격성과의 상관에 있어 냉 담-무정서의 하위요인별로 살펴볼 필요성이 제기되었다. 대 만 청소년을 대상으로 냉담-무정서와 공격성의 상관을 살펴본 Wang 등(2018)의 연구에서는 높은 냉담성은 언어적, 물리적, 신체적 괴롭힘 행동과 정적으로 상관이 있음을 보고하였고, 냉담-무정서가 괴롭힘 예방과 보호프로그램개발에서 고려되 어야한다고 제언하였다. 이러한 냉담-무정서 특질의 영향에 대해서는 국내 뿐 아니라 아시아지역 국가를 대상으로 한 연 구가 아직 부족한 편이다(Sng et al., 2018).

한편, 이러한 냉담-무정서가 공격성에 미치는 영향은 개인 이 가진 다른 특질인 자아상에 따라 달라질 수 있다. 공격성이 
자신과 상대방의 관계에서 발현되는 행동임을 고려할 때, 상 대방에 대한 감정상태를 의미하는 냉담-무정서와 같은 정서 적인 특징이 공격성의 발현에 영향을 미치는 과정에서 공격적 인 행동의 주체인 자기 자신에 대한 인식이 어떠한 작용을 할 것인지에 대한 탐색도 함께 이루어져야 할 필요가 있다. 건강 한 자아를 발달시킨 청소년의 경우 자신의 행동에 대해서도 건강하고 사회적으로 수용되는 방식인지를 인식하고 선택할 수 있을 것이기 때문이다. 냉담-무정서의 특징이 공격성을 유 발하는 과정에서 작용하는 자아의 문제에 대해 접근하기 위해 본 연구는 자기애의 역할에 대해 탐색하고자 하였다.

교육부에서 실시한 '2018년 제1차 학교폭력 실태조사'에 따 르면, 최근 초중고 학생 중 5 만 여명이 학교에서 폭력을 경험 했다고 보고한바 있다(Ministry of Education, 2018). 즉, 지난해 조사보다 약 1 만 3 천명이 늘어난 전체 응답자의 $1.3 \%$ 가 학교 에서 폭력을 경험했으며, 이러한 학교폭력은 학교급별로 조금 씩 다른 양상으로 나타났다. 특히 고등학생의 경우, 초등학생 이나 중학생과는 달리 집단이 아닌 단독으로 가해를 하는 경 우가 더 많았으며, 가해 이유 또한 초등학생과 중학생이 각각 '먼저 괴롭혀서'(28.9\%), '장난으로'(22.6\%)라고 가장 많이 보 고한 것과 달리, 고등학생은 '마음에 안들어서'(22.0\%)를 가 장 큰 가해이유로 꼽았다. 이러한 결과는 고등학교 시기 폭력 성의 특수성을 반영한다. 아동후기와 초기청소년기에는 또래 가 중요한 타인으로 부각되어 또래집단에서 소속, 인정받고 자하는 욕구가 강해지기 때문에(A. K. Kim, 2001) 집단을 통 한 사회관계적 이유를 가진 가해행동이 뚜렷한 반면, 후기 청 소년기는 자신 내에 존재하는 '영속적인 동질성(self-sameness)' 을 발견하여 이를 타인과 공유하고자 하는 '자아정체감(egoidentity)'을 발달시키는 시기이기 때문에(Erikson, 1968), 스스 로에 대한 자아상을 반영한 개인적 이유의 단독 가해행동이 주를 이루는 것으로 추측해볼 수 있다. Swann, Stein-Seroussi와 Giesler (1992)의 정체감 교섭과정(identity negotiation)이론에 따르면, 개인은 자기인식과 타인의식의 상호작용을 통해 정체 감을 형성한다고 보았다. 다시 말해, 스스로에 대한 지각과 타 인이 자신을 어떻게 보는지에 대한 지각을 통해 정체감을 발 달시켜 나간다는 것이다.

공격성을 연구해 온 학자들은 공격적인 사람들의 자아가 부정적이기만 한 것이 아니라 자기관이 긍정적이기도 하다는 점을 발견하였고, 다소 과장되게 긍정적이거나 불안정하게 자 신을 평가한다는 사실을 발견했다(Baumeister, Smart, \& Boden, 1996; Kernis, Cornell, Sun, Berry, \& Harlow, 1993). 이는 자기애 의 특성으로, 자기애는 자아에 대한 건강한 존중이 아닌 과장
된 자기인식과 더불어 자신의 존재와 역할에 대해 부적절한 평가를 하고 있는 상태로, 이들의 자아는 매우 취약하다. 그러 므로 자기애가 강한 사람들은 다양한 대인간 매커니즘과 개 인내적 매커니즘을 통해 과장된 자아를 유지하기 위해 끊임 없이 주의를 기울이고 노력한다(Öngen, 2010). 이러한 이유로 자기애가 지나치게 강하면 자기 자신의 존재감을 확인하기 위 해 사회적으로 부적절한 행동인 공격성을 표현할 가능성이 있 다. 이러한 자기애와 공격성의 관계에 대해서는 선행연구를 통해 확인되었으며, 대부분의 연구는 자기애가 높은 경우 공 격성이 높아지는 것으로 보고하였다(Cha \& Lim, 2016; Lim, 2012). 국외 연구에서도 자기애 성향이 높은 청소년은 공격성 의 수준도 높은 것으로 보고한 바 있다(Barry et al., 2018; Hart, Richardson, \& Breeden, 2019). 또한 대학생을 대상으로 한 연구 에서도 자기애와 공격성의 높은 정적 상관을 보고되기도 하였 다(Okada, 2010; Öngen, 2010). 선행연구들에 의하면, 자기애 가 강한 개인은 자아존중감이 취약하며(Baumeister, Bushman, \& Campbell, 2000; Cale \& Lilienfeld, 2006; Zeigler-Hill \& Besser, 2013), 그래서 자아의 표현을 과장하게 된다(Myers \& ZeiglerHill, 2012). 이러한 내적 기제는 반사회적인 행동의 표출로 이 어져 공격성이 높아지는 결과를 가져오게 된다.

자기애 또는 자아의 측면과 냉담-무정서가 상호작용하여 공격성의 관계에 영향을 미치는지에 대한 연구는 많지 않으 나, 냉담-무정서와 공격성의 관계가 자아의 탈억제수준에 따 라 달라지며(Wright et al., 2019), 자아존중감의 수준에 따라 달 라진다는 연구결과가 보고된 바 있다(Barry et al., 2018). 특히 Barry 등(2018)의 연구에서는 냉담-무정서의 특질을 가진 개인 이 더 공격적으로 행동하는 경우는 타인의 평가에 대한 반응 으로 형성된 자존감이 높은 집단이라고 설명하였다. 즉, 냉담무정서와 공격성의 상관이 스스로 형성한 자아전체에 대한 평 가로서의 자존감이 아니라 타인의 평가에 좌우되어 다소 유 동적이고 불안정한 자아의 한 측면이 높게 나타나는 정도와 관련이 있다는 것을 밝혔고, 자아의 이러한 특징은 불안정하 고 과장된 자아의 한 측면인 자기애의 성격과 가까이 닿아 있 다는 것을 알 수 있다. 그러나 이러한 냉담-무정서와 자기애가 상호작용하여 공격성에 영향을 미치는지 여부에 대해서는 연 구가 크게 이루어지지 않았으며, 특히 나날이 공격성의 수위 가 높아지고 있는 청소년기에 대한 접근은 많지 않다.

성인기로의 진입을 앞두고 건강한 정서적 경험을 통해 자 아정체감을 발달시켜야 하는 고등학교 시기의 공격성이 더욱 심각하게 인식되는 점은 공격성의 표출과정에서 나타나는 개 인의 정서적인 측면과 자기에 대한 이해의 측면에서 부정적 
인 부분이 있기 때문이라는 추정을 가능하게 한다. 이에 본 연 구에서는 청소년의 공격성을 예측하는 정서적인 측면과 자기 이해의 측면을 살펴보아, 청소년의 공격성이 심화되는 현상에 대한 이해를 돕고자 하였다.

따라서 본 연구에서는 강한 공격성이 나타나는 청소년기를 대상으로 냉담-무정서와 자기애가 공격성에 미치는 주효과와 상호작용효과를 분석하고자 하였다. 이를 위해 본 연구에서 설정한 연구문제는 다음과 같다.

\section{연구문제 1}

고등학생의 냉담-무정서, 자기애, 공격성은 어떠한 상관이 있 는가?

\section{연구문제 2}

고등학생의 냉담 - 무정서와 자기애는 공격성에 영향을 미치 는가?

\section{연구문제 3}

고등학생의 냉담-무정서와 자기애는 상호작용하여 공격성에 영향을 미치는가?

\section{Methods}

\section{연구대상}

본 연구의 대상은 전국의 고등학교에 재학 중인 1 학년 2 학 년 학생 315 명이었다. 온라인조사기관 마크로밀 엠브레인을 통해서 참가자를 모집하여 2017년 7월 4일부터 5일까지 온라 인설문을 통해 자료를 수집하였다. 연구대상의 성별은 남학생 이 155 명(49.2\%), 여학생이 160 명(50.8\%)이었고, 평균연령은 만 16.6세였다. 학년의 경우 고등학교 1학년이 127 명(40.3\%), 고등학교 2학년이 188 명(59.7\%)이었다. 연구대상의 자세한 인구통계학적 특성은 아래의 Table 1과 같다.

\section{연구도구}

\section{냉담-무정서 척도}

냉담-무정서 척도는 Frick (2003)이 개발하고 Kwon, Son과 Hwang (2010)이 번안, 타당화한 한국판 청소년 정서적 결핍
Table 1

Demographic Characteristics of Participants

\begin{tabular}{|c|c|c|c|}
\hline & Variables & Frequency & Proportion (\%) \\
\hline \multirow{2}{*}{ Gender } & Boys & 155 & 49.2 \\
\hline & Girls & 160 & 50.8 \\
\hline \multirow{4}{*}{ Age } & 15 & 5 & 1.6 \\
\hline & 16 & 125 & 39.7 \\
\hline & 17 & 179 & 56.8 \\
\hline & 18 & 6 & 1.9 \\
\hline \multirow{2}{*}{$\begin{array}{l}\text { Grade } \\
\text { (High school) }\end{array}$} & Grade 1 & 127 & 40.3 \\
\hline & Grade 2 & 188 & 59.7 \\
\hline \multirow{17}{*}{ Home region } & Seoul & 63 & 20.0 \\
\hline & Busan & 23 & 7.3 \\
\hline & Daegu & 23 & 7.3 \\
\hline & Incheon & 21 & 6.7 \\
\hline & Gwangju & 11 & 3.5 \\
\hline & Daejeon & 9 & 2.9 \\
\hline & Ulsan & 8 & 2.5 \\
\hline & Gyeonggi-do & 91 & 28.9 \\
\hline & Gangwon-do & 8 & 2.5 \\
\hline & Chungcheongbuk-do & 8 & 2.5 \\
\hline & Chungcheongnam-do & 7 & 2.2 \\
\hline & Jeollabuk-do & 2 & 0.6 \\
\hline & Jeollanam-do & 9 & 2.9 \\
\hline & Gyeongsangbuk-do & 14 & 4.4 \\
\hline & Gyeongsangnam-do & 11 & 3.5 \\
\hline & Jeju-do & 6 & 1.9 \\
\hline & Sejong & 1 & 0.3 \\
\hline
\end{tabular}

Note. $N=315$.

척도(Korean Inventory of Callous-unemotional traits [K-ICU]) 를 사용하였다. 하위요인은 세 가지로 구분되는데, 죄책감과 공감의 부족 및 타인에 대한 냉담한 태도를 포함하는 냉담성 (callousness), 일의 수행이나 대인관계에서의 조심성 혹은 세심 함 부족을 의미하는 부주의/무신경(uncaring), 그리고 감정표 현의 부재를 의미하는 감정표현결여(unemotional)를 포함한다 (Kwon et al., 2010). 냉담성에 대한 문항의 예로는 "나는 내가 하는 일에 대해 깊이 신경 쓰지 않는다.”가 있으며, 부주의/무 신경에 대한 문항의 예로는 "나는 다른 사람의 기분에 대해 신 경을 쓴다."(역문항)가 있다. 감정표현결여의 예로는 “나는 다 른 사람들에게 내 기분을 숨긴다.” 등이 있다. 문항의 수는 각 각 냉담성이 10 문항, 부주의/무신경이 9문항, 감정표현결여가 5 문항으로 총 24 문항이다. 이 검사는 전혀 아니다(0점), 약간 아니다(1점), 약간 그렇다(2점), 매우 그렇다(3점)까지 선택할 수 있는 4점 리커트식 척도로 구성되어 있으며, 점수가 높을수 록 냉담-무정서의 정도가 높은 것을 의미한다. 검사의 신뢰도 
(Cronbach's $\alpha$ )는 하위요인별로 냉담성이 .79, 부주의/무신경 이 .75, 감정표현결여가.78로 나타났다.

\section{자기애 척도}

자기애 척도는 Hwang (1995)이 개발하고 Han (1999)이 수정 한 자기애 성격 장애 척도(Narcissistic Personality Disorder Scale [NPDS])를 사용하였다. 원척도는 총 18 문항이며, 하위요인은 세 가지로 웅대성/칭찬과 주목에 대한 욕구(grandiosity/desire for praise and attention), 자기중심성(egocentrism), 그리고 과장 된 자기지각(exaggerated self-perception)이다. 웅대성/칭찬과 주 목에 대한 욕구에 대한 문항의 예로는 "누군가가 나를 좋지 않 게 평가하면 화가 치밀거나 수치심이나 모욕감을 느낀다."가 있으며, 자기중심성에 대한 문항의 예로는 "내 주변에 있는 사 람들의 의견을 하찮게 생각하며, 그들을 무시하고 내가 하고 싶은 대로 하는 편이다.”가 있다. 본 척도는 7점 리커트 척도로 구성되어 있으며, 전혀 그렇지 않다(1점)부터 약간 그렇다(3 점), 상당히 그렇다(5점), 전적으로 그렇다(7점)까지 1점에서 7 점까지 선택할 수 있도록 구성되어 있으며, 점수가 높을수록 자기애가 높은 것을 의미한다. 본 척도의 신뢰도(Cronbach's $\alpha$ )는 각 하위요인별로 웅대성/칭찬과 주목에 대한 욕구가 .86, 자기중심성이 .80 이었으며, 신뢰도가 .41로 나타난 과장된 자 기지각은 분석에서 제외되어, 웅대성/칭찬과 주목에 대한 욕 구 8문항, 자기중심성 8문항, 총16문항이 포함되었다. 본 연구 에서는 웅대성/칭찬과 주목에 대한 욕구는 웅대한 자기상을 바탕으로 타인의 인정이나 존경을 받으려는 과도한 욕구로 정 의하며, 자기중심성은 타인의 생각이나 입장을 고려하지 않고 자신만을 중심으로 하는 태도로 정의하고자 한다.

\section{공격성 척도}

공격성을 측정하기 위하여 사용한 측정도구는 Buss와 Durkee (1957)가 제작한 Buss-Durkee Hostility Inventory (BDH)에 기 초하여 Rho (1983)가 번안한 것을 J. I. Kim (2003)이 사용한 것을 사용하였다. 방어적 반응적 공격성, 기질적 자발적 공격 성, 공격성표현의 통제력, 자기주장적 태도 등의 내용으로 구 성되어 있으며, 총 21 개 문항이다. 방어적 반응적 공격성에 대 한 문항의 예로는 "누가 먼저 나를 때린다면 나도 때리겠다." 가 있으며, 기질적 자발적 공격성에 대한 문항의 예는 "나는 때때로 다른 사람을 해치고 싶은 충동을 억제할 수 없다." 등 이 있다. 공격성표현의 통제력의 예로는 "나는 매우 흥분했을
때 누군가를 때릴 수 있다.”가 있으며, 자기주장적 태도의 예 로는 "사람들이 나에게 동의하지 않을 때는 논쟁을 할 수밖에 없다.” 등이 있다. 문항은 총21문항으로 전혀 아니다(1점)에서 약간 그렇다(2점), 꽤 그렇다(3점), 아주 그렇다(4점)까지 선택 할 수 있는 4점 리커트식 척도로 구성되었으며, 검사의 신뢰도 (Cronbach's $\alpha$ )는 .90이었다.

\section{자료분석}

수집된 자료의 분석을 위해 SPSS 21.0 (IBM Co., Armonk, NY) 통계 프로그램을 사용하였다. 첫째, 참가자의 인구통계학적 특성을 살펴보기 위하여 기술통계를 사용하였다. 둘째, 변인 들 간의 상관관계를 검증하기 위하여 Pearson의 단순상관 분석 을 하였다. 셋째, 고등학생의 냉담-무정서와 자기애가 공격성 에 미치는 영향을 알아보기 위하여 중다회귀분석을 실시하였 다. 넷째, 고등학생의 냉담-무정서와 자기애가 상호작용하여 공격성에 영향을 미치는지를 검증하기 위해서 단계적 중다회 귀분석을 실시하였다.

\section{Results}

\section{측정변인들의 일반적 경향}

각 변인의 평균과 표준편차를 산출한 결과는 아래의 Table 2 와 같다. 먼저 냉담-무정서의 하위변인들을 살펴보면, 냉담성 총점의 평균은 4점 만점에 1.93 으로 나타났으며, 부주의/무신 경은 1.99 , 감정표현결여는 2.63 으로 나타났다. 이를 7점 척도 의 문항평균점수로 환산하면 냉담성이 3.38 , 부주의/무신경이 3.48 , 감정표현결여가 4.61이었다. 즉, 고등학생들의 냉담-무 정서 수준은 감정표현결여, 부주의/무신경, 그리고 냉담성 순 으로 높게 나타났다. 다음으로 자기애의 하위요인을 살펴보 면, 고등학생들의 자기애는 웅대성/칭찬과 주목에 대한 욕구 $(M=3.57, S D=1.11)$, 자기중심성 $(M=2.95, S D=0.95)$ 순으로 높게 나타났다. 마지막으로 공격성은 7점 척도의 문항평균점 수로 환산하였을 때 3.76 으로 나타나 중간 점수를 다소 상회 하는 것으로 나타났다. 
Table 2

Means and Standard Deviations of the Variables

\begin{tabular}{|c|c|c|c|}
\hline Variables & Score range & $M(S D)$ & $\begin{array}{c}\text { Mean of item score } \\
(S D)\end{array}$ \\
\hline Callous-unemotional traits: Callousness & $\begin{array}{c}3.00 \\
(1.00 \sim 4.00)\end{array}$ & $1.93(.46)$ & $3.38(.80)$ \\
\hline Callous-unemotional traits: Uncaring & $\begin{array}{c}2.22 \\
(1.00 \sim 3.22)\end{array}$ & $1.99(.41)$ & $3.48(.71)$ \\
\hline Callous-unemotional traits: Unemotional & $\begin{array}{c}3.00 \\
(1.00 \sim 4.00)\end{array}$ & $2.63(.58)$ & $4.61(1.02)$ \\
\hline Narcissism: Grandiosity/desire for praise and attention & $\begin{array}{c}5.75 \\
(1.00 \sim 6.75)\end{array}$ & $3.57(1.11)$ & $3.57(1.11)$ \\
\hline Narcissism: Egocentrism & $\begin{array}{c}4.38 \\
(1.13 \sim 5.50)\end{array}$ & $2.95(.95)$ & $2.95(.95)$ \\
\hline Aggression & $\begin{array}{c}2.19 \\
(1.24 \sim 3.43)\end{array}$ & $2.15(.40)$ & $3.76(.70)$ \\
\hline
\end{tabular}

Note. $N=315$.

Table 3

Correlations Among the Variables

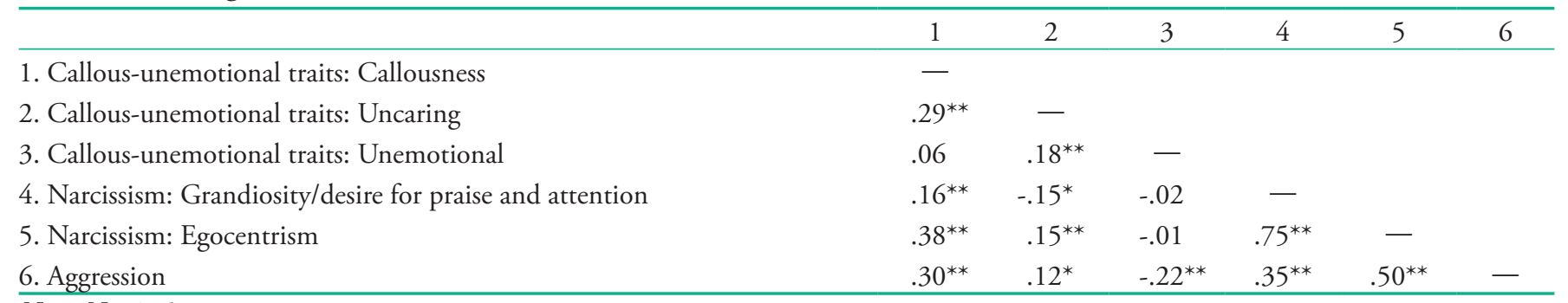

Note. $N=315$.

${ }^{*} p<.05 .{ }^{* *} p<.01$.

\section{고등학생의 냉담-무정서, 자기애, 공격성의 상관관계}

고등학생의 냉담-무정서, 자기애, 공격성의 상관관계를 살펴 보기 위해 냉담-무정서와 자기애의 하위변인 및 공격성 간의 Pearson의 상관계수를 살펴본 결과는 Table 3 과 같다. 먼저 냉 담무정서의 하위변인과 자기애의 하위변인간의 상관을 살펴 보면, 냉담무정서의 첫 번째 하위변인인 냉담성은 자기애의 하위변인인 웅대성/칭찬과 주목에 대한 욕구 $(r=.16, p<.01)$, 자기중심성 $(r=.38, p<.01)$ 과 정적상관을 보였고, 냉담무정서 의 두 번째 하위변인 부주의/무신경은 자기애 하위변인인 웅 대성/칭찬과 주목에 대한 욕구 $(r=-.15, p<.05)$ 와 부적상관을, 자기중심성 $(r=.15, p<.01)$ 과는 정적상관을 나타냈다. 냉담무 정서의 마지막 하위변인 감정표현 결여는 자기애의 하위변인 들과 유의한 상관을 나타내지 않았다. 다음으로 냉담무정서의 하위변인과 공격성 간의 상관을 알아보면, 공격성은 냉담무정
서의 하위변인 냉담성 $(r=.30, p<.01)$, 부주의/무신경 $(r=.12$, $p<.05)$ 과는 정적상관을 나타냈으며, 감정표현결여 와는 부적 상관 $(r=-.22, p<.01)$ 을 나타내었다. 마지막으로 자기애의 하 위변인들과 공격성 간의 상관을 살펴보면, 공격성은 자기애의 하위변인 웅대성/칭찬과 주목에 대한 욕구 $(r=.35, p<.01)$, 자 기중심성 $(r=.50, p<.01)$ 모두와 정적상관을 나타내었다.

\section{고등학생의 공격성에 대한 냉담-무정서와 자기애의 영향}

고등학생의 냉담-무정서와 자기애가 공격성에 미치는 영향을 알아보기 위해 냉담-무정서의 하위변인인 냉담성, 부주의/무 신경, 감정표현결여와 자기애의 하위변인 웅대성/칭찬에 대 한 욕구, 자기중심성을 독립변인으로 두고 공격성을 종속변인 으로 하여 중다회귀분석을 실시하였다(Table 4). 그 결과 설명 력은 $31 \%$ 를 나타냈다. 구체적으로, 자기애의 하위요인 중 자 
Table 4

Effects of Callous-Unemotional Traits and Narcissism on Aggression

\begin{tabular}{lcc}
\hline & \multicolumn{2}{c}{ Aggression } \\
\cline { 2 - 3 } & \multicolumn{2}{c}{$\beta$} \\
\hline Callous-unemotional traits: Callousness & .12 & $.14^{* *}$ \\
$\quad$ Uncaring & .07 & .07 \\
$\quad$ Unemotional & -.16 & $-.24^{* * *}$ \\
Narcissism: Grandiosity/desire for praise and attention & .01 & .03 \\
$\quad$ Egocentrism & .17 & $.41^{* * *}$ \\
$F(d f 1, d f 2)$ & & $28.32^{* *}(5,309)$ \\
$R^{2}$ & & .31 \\
\hline
\end{tabular}

Note. $N=315$.

${ }^{* *} p<.01 .{ }^{* * *} p<.001$.

Table 5

Interaction Effects of Callousness and Egocentrism on Aggression

\begin{tabular}{|c|c|c|c|c|}
\hline & \multicolumn{2}{|c|}{ Step 1} & \multicolumn{2}{|c|}{ Step 2} \\
\hline & $B$ & $\beta$ & $B$ & $\beta$ \\
\hline Callousness & .12 & $.13^{*}$ & .14 & $.16^{* *}$ \\
\hline Egocentrism & .19 & $.44^{* * *}$ & .19 & $.46^{* * *}$ \\
\hline Callousness x Egocentrism & & & -.08 & $-.10^{*}$ \\
\hline$F$ & \multicolumn{2}{|c|}{$54.92^{* * *}$} & \multicolumn{2}{|c|}{$38.28^{* * *}$} \\
\hline$\Delta F$ & \multicolumn{2}{|c|}{$54.92^{* * *}$} & \multicolumn{2}{|c|}{$3.96^{*}$} \\
\hline$R^{2}$ & \multicolumn{2}{|c|}{.26} & \multicolumn{2}{|c|}{.27} \\
\hline$\Delta R^{2}$ & \multicolumn{2}{|c|}{.26} & \multicolumn{2}{|c|}{.01} \\
\hline
\end{tabular}

${ }^{*} p<.05 .{ }^{* *} p<.01 .{ }^{* * *} p<.001$.

기중심성 $(\beta=.41, p<.001)$ 과 냉담-무정서의 하위변인인 냉담 성 $(\beta=.14, p<.01)$ 이 공격성에 유의한 정적 영향을 미쳤으며, 냉담-무정서의 하위변인인 감정표현결여는 공격성에 유의한 부적 영향을 미쳤다 $(\beta=-.24, p<.001)$. 즉, 고등학생의 자기중 심성과 냉담성이 높을수록, 감정표현결여 수준은 낮을수록 높 은 공격성을 보였다.

\section{고등학생의 공격성에 대한 냉담-무정서와 자기애의 상호작용효과}

고등학생의 공격성에 대한 냉담-무정서와 자기애의 상호작용 효과를 검증하기에 앞서, 상호작용항의 투입으로 인한 다중공 선성의 문제를 줄이기 위해 독립변인인 냉담-무정서와 자기 애의 각각의 하위변인들을 원 점수에서 평균값을 뺀 평균중심 화(centering)로 변환하여 냉담-무정서의 하위변인과 자기애의
하위변인을 곱한 상호작용변인들을 만든 후 총6개의 모델에 대해 단계적 중다회귀분석을 실시하였다. 평균중심화 후 상 호작용항의 분산팽창지수(VIF)는 $1.00 \sim 1.15$ 로 다중공선성에 문제가 없는 것으로 나타났다.

고등학생의 공격성에 대한 냉담-무정서와 자기애의 상호 작용효과를 검증하기 위해서 독립변인인 냉담-무정서와 자기 애의 각각의 하위변인들을 원 점수에서 평균값을 뺀 평균중심 화로 변환하여 냉담-무정서의 하위변인과 자기애의 하위변인 을 곱한 상호작용변인들을 만든 후 단계적 중다회귀분석을 실 시하였다. 그 결과 $R$ 제곱 값이 1,2 단계로 갈수록 커지고, 유의 확률 $F$ 변화량이 모두 유의하여 상호작용효과가 유의미하게 나타난 모델은 총2가지로, 이 상호작용효과를 분석한 결과는 Table 5, Table 6에 제시된 바와 같다.

먼저, 고등학생의 공격성에 미치는 냉담성과 자기중심성의 주효과 검증을 위해 1 단계에서 냉담성과 자기중심성을 동시 
에 투입한 결과, 냉담성 $(\beta=.13, p<.05)$ 과 자기중심성 $(\beta=.44$, $p<.001)$ 모두 유의한 영향력을 미치는 것으로 나타났으며, 두 변인은 함께 고등학생의 공격성 분산의 $26 \%$ 를 설명하는 것으 로 나타났다. 2 단계에서 냉담성과 자기중심성의 상호작용항 을 추가로 투입한 결과, 고등학생의 공격성에 미치는 냉담성 과 자기중심성의 상호작용효과는 통계적으로 유의미하게 나 타났으며 $(\beta=-.10, p<.05)$, 추가로 $1 \%$ 를 더 설명하여 총 $27 \%$ 를 설명하였다(Table 5).

다음으로, 고등학생의 공격성에 미치는 부주의/무신경과 자기중심성의 주효과를 알아보기 위해 1 단계에서 부주의/무 신경과 자기중심성을 동시에 투입한 결과, 자기중심성만이 유 의한 영향력을 미치는 것으로 나타났으며 $(\beta=.49, p<.001)$, 두 변인은 고등학생의 공격성 분산의 $25 \%$ 를 설명하는 것으 로 나타났다. 부주의/무신경과 자기중심성의 상호작용효과를 알아보기 위해 2 단계에서 두 변인의 상호작용항을 추가로 투 입한 결과, 상호작용효과는 통계적으로 유의미하게 나타났으 며 $(\beta=-.18, p<.001)$, 상호작용항은 추가로 $3 \%$ 를 더 설명하여 총 $28 \%$ 를 설명하였다(Table 6).

Table 6

Interaction Effects of Uncaring and Egocentrism on Aggression

\begin{tabular}{lcccc}
\hline & \multicolumn{2}{c}{ Step 1 } & \multicolumn{2}{c}{ Step 2 } \\
\cline { 2 - 5 } & $B$ & $\beta$ & $B$ & $\beta$ \\
\hline Uncaring & .05 & .05 & .05 & .05 \\
Egocentrism & .21 & $.49^{* * *}$ & .21 & $.50^{* * *}$ \\
Uncaring x Egocentrism & & & -.17 & $-.18^{* * *}$ \\
$F$ & $51.34^{* * *}$ & \multicolumn{2}{c}{$40.19^{* * *}$} \\
$\Delta F$ & $51.34^{* * *}$ & \multicolumn{2}{c}{$13.71^{* * *}$} \\
$R^{2}$ & \multicolumn{2}{c}{.25} & \multicolumn{2}{c}{.28} \\
$\Delta R^{2}$ & \multicolumn{2}{c}{.25} & \multicolumn{2}{c}{.03} \\
\hline
\end{tabular}

${ }^{* * *} p<.001$.

유의미한 상호작용효과를 Figure 1, Figure 2를 통해 살펴보 면 다음과 같다. 먼저 Figure 1을 보면, 자기중심성이 낮은 집단 $(M-S D, S D=.95)$ 에 비해 높은 집단 $(M+S D, S D=.95)$ 의 공격성 은 더 높게 나타났으며, 자기중심성이 높은 경우에는 냉담성 의 수준이 높고 낮음에 따라 공격성의 큰 차이가 없었으나, 자 기중심성이 낮은 경우에는 냉담성의 수준이 높을수록 공격성 이 높아졌다. 이러한 경향은 Figure 2에도 비슷하게 나타나는 데, 자기중심성이 낮은 집단에 비해 높은 집단의 공격성이 더 크게 나타났으며, 자기중심성이 높은 경우에는 부주의/무신 경의 수준이 높고 낮음에 따라 공격성의 차이가 크지 않았으
나, 자기중심성이 낮은 경우에는 부주의/무신경의 수준이 높 을수록 공격성이 높아졌다.

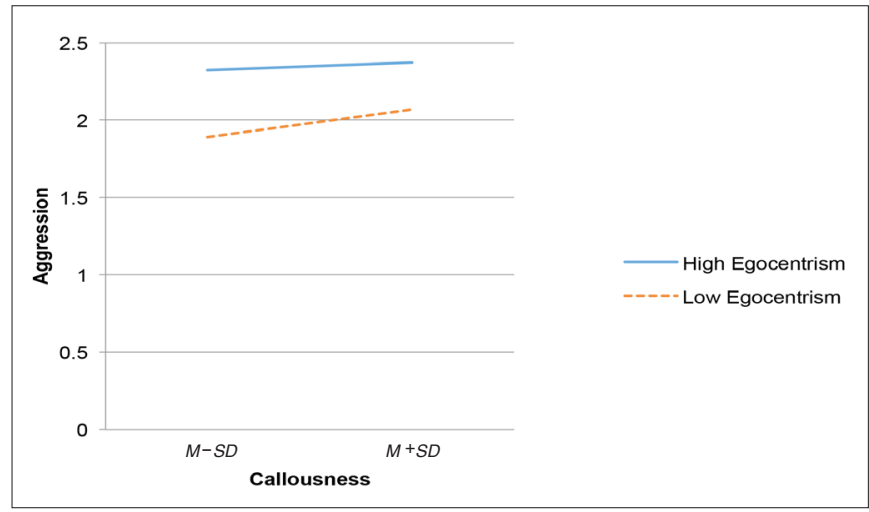

Figure 1. Interaction effects of callousness and egocentrism on aggression.

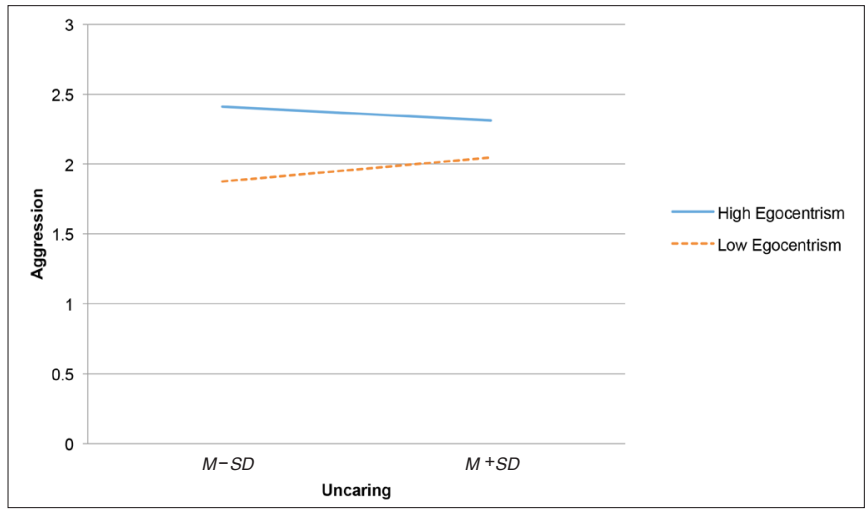

Figure 2. Interaction effects of uncaring and egocentrism on aggression.

\section{Discussion}

본 연구는 공격성이 심화되어 나타나는 청소년기인 고등학생 을 대상으로 공격성을 예측하는 변수 중 정서적인 측면과 자 기이해의 측면을 살펴보고자 하는 목적 하에, 냉담-무정서와 자기애가 공격성에 미치는 영향 및 이들이 상호작용하여 고등 학생의 공격성에 미치는 영향을 분석해보았다. 그 결과 고등 학생의 냉담-무정서와 자기애는 부분적으로 공격성에 유의미 한 영향을 미쳤으며, 냉담-무정서와 자기애는 부분적으로 상 호작용하여 공격성에 유의미한 영향을 미치는 것으로 나타났 다. 그 결과에 대해 논의해보면 다음과 같다.

첫째, 냉담-무정서와 자기애는 모두 공격성과 유의한 상관 을 보였다. 냉담-무정서 중 냉담성과 부주의/무신경은 공격성 과 정적 상관을 보였고, 감정표현결여는 공격성과 부적 상관 
을 보여 대조를 이루었다. 냉담-무정서를 구성하는 하위개념 에는 세 하위변인이 논리적 근거를 가지고 있으나 공격성과 의 관련에 있어서는 그 직접적인 상관이 다소 다른 것이다. 냉 담성과 부주의/무신경이 높을수록 공격성이 높아진 결과로 미루어보아, 후회, 죄책감의 결여, 또는 주요한 과제나 대인 관계에 대한 관심의 결여 등 정서와 주의의 결핍이라는 공통 점이 상대방의 입장이나 감정에 공감할 기회를 감소시켜 높 은 공격성이 나타나는 것으로 해석할 수 있다. 반면, 감정표현 결여는 공격성과 부적상관을 보였는데, 이는 감정표현결여의 경우 “나는 다른 사람들에게 내 기분을 숨긴다."와 같은 문항 의 예에서 알 수 있듯이 긍정적 감정뿐 아니라 부정적 감정 모 두를 포함하는 일반적 감정의 상태를 타인에게 표현하지 않 는 것을 나타내기 때문에, 공격성을 촉발하는 분노나 적대감 과 같은 감정표현이 발현될 가능성이 적어져, 결과적으로 공 격성과 부적인 상관이 나타났을 것으로 판단된다. 이러한 본 연구의 결과는 냉담성과 부주의/무신경이 오프라인 및 사이 버괴롭힘 행동에 대해 정적 영향을 미치고 감정표현결여는 유 의한 영향을 미치지 않았다고 보고한 Wright 등(2019)의 연구 및 감정표현결여가 직접적 괴롭힘과 사이버 괴롭힘 모두와 관련이 없다고 보고한 선행연구들(Fanti, Demetriou, \& Hawa, 2009; Kokkinos \& Voulgaridou, 2017)과도 부분적으로 일치한 다. 연구자들은 이에 대해 냉담-무정서의 하위요인 중 냉담성 과 부주의/무신경 만이 공감, 후회, 죄책감, 혹은 타인에게 잘 못된 행동을 하는 것에 대한 염려의 부족과 연관이 있기 때문 (Kokkinos \& Voulgaridou, 2017)으로 추론한 바 있다. 또한 이 러한 결과는 공격성을 유발하거나 예측하는 정서적 요인, 자 기이해의 요인 들을 고려할 때 각 정서변인이나 자아변인을 단일한 성격으로 규정하기보다는 세부적인 측면을 살펴보아 공격성과의 상관에 대해 다양한 고려를 해야 한다는 점을 시 사한다.

자기애의 두 요인은 모두 공격성과 정적 상관을 보였고, 특 히 자기중심성과 공격성의 상관이 가장 높게 나타났다. 공격 성과 자기중심성의 상관이 공격성과 냉담-무정서의 상관보다 훨씬 크게 나타난 점은 주목할 만하다. 냉담-무정서와 같이 정 서의 비활성화 문제보다 타인의 감정이나 입장을 고려하지 못 하는 자기중심적인 태도가 공격성과 훨씬 더 큰 관련이 있다 는 것이며, 이는 후기 청소년기 공격성을 이해하고 원인과 해 법을 찾기 위해 건강한 자기개념을 바탕으로 타인을 고려하고 공감할 수 있는 태도를 기를 수 있도록 점검하는 단계가 필요 함을 암시한다.

둘째, 고등학생의 냉담-무정서와 자기애는 공격성에 부분
적으로 영향을 미쳤다. 구체적으로 냉담-무정서의 하위요인 인 냉담성은 공격성에 정적인 영향을 미쳤으며, 감정표현결여 는 부적인 영향을 미쳤다. 냉담-무정서의 하위요인인 부주의/ 무신경은 공격성에 유의미한 영향을 미치지 않았다. 또한 자 기애의 하위요인인 자기중심성은 공격성에 유의미한 정적영 향을 미쳤으며, 또 다른 하위변인인 웅대성/칭찬과 주목에 대 한 욕구는 유의미한 영향을 미치지 않았다. 이러한 결과는 냉 담-무정서의 하위요인 중 냉담성과 부주의/무신경만이 익명 과 실명의 사이버 괴롭힘에 유의한 영향을 미쳤다고 보고한 선행연구(Wright et al., 2019)의 결과와 부분적으로 일치한다. 냉담-무정서의 하위요인 중 공감, 후회, 죄책감의 결여와 관계 가 있는 냉담성은 공격성에 유의한 주효과가 있었음이 입증되 었으나, 선행연구와 달리 본 연구에서는 부주의/무신경의 주 효과는 유의하지 않았다. 이러한 이유는 11-14세 청소년을 대 상으로 한 선행연구와 달리(Wright et al., 2019), 본 연구에서는 보다 인지적으로 성숙한 고등학교 1-2학년 학생을 대상으로 하였기 때문에, 학교과제나 대인관계과제와 같은 과제수행에 대한 관심이 적은 것을 의미하는 부주의/무신경이 사회적 상 황에서 공격성으로 나타나는 데 대한 독립적인 영향력이 크지 않았을 것으로 사료된다. 그러나 이러한 주효과의 검증결과는 상호작용효과의 결과와 함께 고려하여 해석할 필요가 있다.

또한 자기애가 공격성에 유의미한 주효과가 있음을 밝힌 선행연구와도 부분적으로 일치하는데(Hart et al., 2019), 본 연 구의 자기애의 하위요인 중 자기중심성의 주효과만이 공격성 에 유의하다는 결과는 자기중심적인 태도를 벗어나 타인의 입 장이나 감정을 이해하려는 태도를 갖는 것이 공격성을 완화 하는 데 있어 중요한 부분임을 시사한다. 반면, 웅대한 자기상 을 바탕으로 타인의 인정이나 존경을 받으려는 과도한 욕구를 의미하는 웅대성/칭찬과 주목에 대한 욕구는 공격성에 유의 미한 주효과를 나타내지 않았는데, 이는 해당 하위요인이 타 인의 평가에 민감하며 웅대한 자기상에 부합하지 않는 타인의 태도에 분노, 수치심과 같은 부정적 감정을 쉽게 느끼는 것을 의미하기는 하나, 이것이 타인에게 실질적인 해를 입히는 결 과를 초래하는 공격성에 이르기까지는 영향력을 미치지 않았 음을 암시한다.

셋째, 고등학생의 공격성에 대한 냉담-무정서와 자기애의 상호작용효과 중 냉담성과 자기중심성, 부주의/무신경과 자 기중심성의 상호작용효과가 유의하였다. 냉담성 또는 부주 의/무신경이 높은 집단에서는 자기중심성의 높고 낮음에 따 라 공격성 수준에 큰 차이가 없었으나, 냉담성 또는 부주의/무 신경이 낮은 경우에는 자기중심성이 높은 집단의 공격성은 자 
기중심성이 낮은 집단보다 크게 높은 것으로 나타났다. 앞서 부주의/무신경이 공격성에 유의미한 주효과를 보이지는 않았 으나, 자기애의 수준에 따라서는 그 영향력이 다르게 작용하 는 것으로 나타난 점이 흥미롭다. Wright 등(2019)의 연구에서 는 온라인 세계에서 자신의 행동의 결과에 대한 관심을 덜 느 끼는 경향인 온라인 탈억제와 냉담-무정서의 상호작용이 사 이버 괴롭힘에 미치는 영향을 알아본 결과, 냉담-무정서의 하 위요인 중 부주의/무신경과 온라인 탈억제 간의 상호작용이 사이버 괴롭힘에 유의한 영향을 미쳤음을 보고했다. 이는 타 인의 생각이나 감정을 고려하지 않고 자신의 욕구를 중심으로 판단하고자 하는 경향인 자기중심성과 냉담-무정서의 하위요 인인 냉담성, 부주의/무신경과의 상호작용이 공격성에 유의 한 영향을 미친 본 연구의 결과와 맥락을 같이한다. 또한 타인 의 평가에 의해 자기평가가 변화하는 경향인 조건부 자존감 과 냉담-무정서의 상호작용이 반응적 공격성에 영향을 미쳤 다고 보고한 선행연구(Barry et al., 2018)와도 맥락을 같이한다. 이러한 결과들은 낮은 자아존중감과의 상관이 나타난 자기애 (Baumeister et al., 2000; Cale \& Lilienfeld, 2006; Zeigler-Hill \& Besser, 2013) 혹은 공고하지 못한 자기상을 바탕으로 한 조건 부 자존감이 높은 청소년들이 정서적으로 차가워졌을 때, 공 격성을 통해 자신이 지각하는 위협적인 상황을 대처하거나 원 하는 사회적 목표를 이루려는 경향이 강해질 수 있음(Barry et al., 2018)을 시사한다.

냉담-무정서의 하위요인 중 냉담성은 공감이나 죄책감의 결여와 냉담한 태도를 바탕으로 하기 때문에 타인을 대상으 로 반응적 정서가 활성화되지 못하여 피해자의 정서에 공감하 지 못한 채 공격성을 보이게 되는 것으로 해석할 수 있고, 부 주의/무신경은 학교과제나 대인관계과제와 같은 일반적으로 중요하게 여겨지는 과제수행에 대한 주의와 관심을 기울이지 않는 성향으로 이러한 성향이 커질수록 피해자와의 대인관계 에 관심을 가지지 않게 하여 큰 고민 없이 공격적인 행동을 할 수 있도록 하는 것으로 추측할 수 있다. 이러한 냉담성이나 부 주의/무신경 성향의 수준이 낮더라도 청소년이 자기중심성을 강하게 가지고 있을 경우에는 상황을 자기중심적으로 해석하 고 상대방의 관점을 고려하지 않아 피해자 입장에 대한 배려 없이 공격적 행동을 할 수 있는 것으로 해석된다.

이러한 결과는 냉담성이나 부주의/무신경이 심각하게 높 은 집단의 경우에는 자기애의 수준에 따른 공격성이 차이가 드러나지 않으나, 냉담성이나 부주의/무신경 수준이 낮은 집 단의 경우에는 자기중심성과 같은 자기애의 수준을 완화시 켜주면 냉담성과 부주의/무신경으로 인해 촉발될 수 있는 공
격적 행동의 표현을 통제할 수 있도록 보호요인으로 작용할 수 있다는 사실을 알려준다. 자기애가 강한 경우 자아존중감 이 취약하며(Baumeister et al., 2000; Cale \& Lilienfeld, 2006; Zeigler-Hill \& Besser, 2013), 그 결과 자아의 표현을 과장하게 되어(Myers \& Zeigler-Hill, 2012), 자아의 과장된 표현으로 인 해 공격적 행동을 표출하게 되므로, 자기애를 완화시키면 과 장된 자아의 표현이 진정되어 공격성의 촉발을 막아줄 것으로 추론된다.

한편, 냉담-무정서와 자기애 중 특히 자기중심성이 공격성 에 대해 유의미한 상호작용효과를 나타낸 결과는 청소년기의 보편적인 발달적 특징과 구분하여 해석할 필요가 있을 것이 다. 청소년기는 급격한 신체변화와 더불어 추상적 사고의 발 달, 타인관점 이해능력의 발달 등으로 인해 상상의 관중이나 개인적 우화 등의 자아중심성이 나타나는 시기로, 이 시기의 일정수준의 자아중심성은 보편적으로 나타나는 현상으로 간 주한다. 그러나 본 연구결과, 자기애에 속하는 자기중심성은 이러한 보편적인 자아중심성과 구분되어 타인을 배려하지 않 고 자신의 욕구와 기준을 중심으로 행동하는 특성으로 구분해 서 이해할 필요가 있다. 이러한 자기애의 일부인 자기중심성 은 보편적으로 나타나는 자아중심성과 달리 타인과의 원만한 관계를 방해할 뿐 아니라 타인에 대한 공격성을 촉진시키는 역할을 하기도 하는 것이다.

본 연구의 의의를 종합하면, 냉담-무정서와 공격성의 관계 는 자기애 중 특히 자기중심성이 높은 집단과 낮은 집단 간에 두드러진 차이를 보이는 것으로 나타났다. 이는 냉담한 성향 과 부주의/무신경한 성향이 심각하지 않은 청소년의 경우 공 격성의 완화는 자기중심성을 벗어나 타인과의 관계를 고려하 고 타인의 입장을 생각하는 능력을 바탕으로 가능하다는 것을 암시하는 결과로, 청소년의 자신에 대한 사랑이 자기중심성이 라는 잘못된 자기애의 형태로 발전하지 않도록 지도해야함을 시사한다. 또한 자기중심성이 낮더라도 냉담성과 부주의/무 신경 등 정서적으로 차가운 상태에서는 공격성이 높아진다는 본 연구결과는, 공격성이라는 원초적 본능을 사회적으로 용납 할만한 수준과 방법으로 통제하기 위해서는 자기중심성을 벗 어난 자아에 대한 건강한 태도를 필요로 할 뿐 아니라 정서적 으로도 긍정적이고 따뜻한 성향을 갖추는 것이 필요하다는 사 실을 알려주며, 청소년의 공격성 감소를 위한 다양한 접근으 로, 인지적 이해와 행동조절능력, 사회적 능력함양을 통한 지 도와 치료 뿐 아니라 다양한 정서를 풍부하게 경험하도록 노 력하고 자아에 대한 합리적이고 객관적인 태도를 갖추도록 노 력하는 과정이 필요하다는 것을 보여준다. 더 나아가 일반 고 
등학생을 대상으로 냉담-무정서와 자기애의 수준에 따라 공 격성이 높아질 수 있음을 보여준 본 연구의 결과는 날로 심각 해지고 있는 국내의 청소년범죄 및 학교폭력의 예방을 위해서 는 현재와 같은 학업중심적인 고등학교환경에서 벗어나, 청소 년들이 청소년기의 발달과업인 건강한 자아개념을 확립하고, 정서적으로 건강한 발달을 할 수 있도록 돕는 교육시스템이 선행되어야 함을 시사한다.

마지막으로, 본 연구의 한계점과 후속연구를 위한 제언은 다음과 같다. 첫째, 냉담-무정서 및 자기애의 각 하위요인별 주효과 및 상호작용효과가 공격성에 미치는 영향을 알아본 본 연구의 결과에서 각 상호작용항의 설명력은 유의미하긴 하나 크지 않은 수준이었다. 이러한 결과는 공격성의 수준이 높지 않은 일반 청소년을 대상으로 했기 때문으로 추측할 수 있다. 따라서 추후연구에서는 공격성이 높은 청소년을 대상으로 냉 담-무정서 및 자기애의 관계를 살펴볼 필요가 있다. 둘째, 본 연구에서는 냉담-무정서와 자기애의 각 하위요인별 효과를 살펴보았으므로, 각 구성개념의 의미를 포괄하는 냉담-무정 서 및 자기애의 영향력을 논하는 데에는 어려움이 있다는 한 계점이 있다. 따라서 추후의 연구에서는 하위요인 간의 관계 뿐 아니라 냉담-무정서, 자기애, 공격성 각각의 포괄적인 개념 간의 관계에 대한 연구가 이루어질 필요가 있다. 또한 본 연구 에서 냉담-무정서의 하위요인 중 감정표현결여의 역할이 다 른 두 하위요인과 다르게 나타난 점에 주목하여, 추후연구에 서는 정서표현의 결핍이 행동문제와 적응에 미치는 영향이 어 떠한지를 좀 더 심도 깊게 접근할 필요가 있다. 셋째, 본 연구 에서는 성에 따른 공격성에 대한 냉담-무정서와 자기애의 주 효과 및 상호작용효과를 살펴보지 않았으나, 후속연구에서는 냉담-무정서와 자기애에서 뚜렷하게 나타난다고 알려진 성의 차이에 대한 예측을 반영하여 남아와 여아를 구분하여 공격성 의 정서적 요인과 자아관련 요인을 살펴볼 필요가 있을 것이 다. 넷째, 본 연구의 데이터는 온라인조사기관을 통해 조사에 응하겠다는 동의를 받는 사람들을 대상으로 하였으므로 지역 별로 회수율의 차이가 불가피하였다는 제한점이 있으며, 추후 연구에서는 보다 정확한 추정을 위해 체계적인 추출방법을 통 한 샘플을 사용할 필요가 있다. 본 연구결과를 통해 공격성에 유의미한 영향력을 가진 것으로 밝혀진 냉담-무정서의 유형 과 자기애의 의미에 대한 지식을 청소년 교육과 치료현장에서 적용하고 활용할 수 있기를 기대한다.

\section{Notes}

This article was presented at the 2018 Fall Conference of the Korean Association of Child Studies.

\section{Conflict of Interest}

No potential conflict of interest relevant to this article was reported.

\section{Reference}

\section{In English}

American Psychiatric Association. (2013). Diagnostic and statistical manual of mental disorders (5th ed.). Arlington, VA: American Psychiatric Association.

Asscher, J. J., van Vugt, E. S., Stams, G. J. J., Deković, M., Eichelsheim, V. I., \& Yousfi, S. (2011). The relationship between juvenile psychopathic traits, delinquency and (violent) recidivism: A meta-analysis. Journal of Child Psychology and Psychiatry, 52(11), 1134-1143. doi:10.1111/ j.1469-7610.2011.02412.x

Barry, C. T., McDougall, K. H., Anderson, A. C., \& Bindon, A. L. (2018). Global and contingent self-esteem as moderators in the relations between adolescent narcissism, callousunemotional traits, and aggression. Personality and Individual Differences, 123, 1-5. doi:10.1016/j.paid.2017.10.036

Baumeister, R. F., Bushman, B. J., \& Campbell, W. K. (2000). Self-esteem, narcissism, and aggression: Does violence result from low self-esteem or from threatened egotism? Current Directions in Psychological Science, 9(1), 26-29. doi:10.1111/1467-8721.00053

Baumeister, R. F., Smart, L., \& Boden, J. M. (1996). Relation of threatened egotism to violence and aggression: The dark side of high self-esteem. Psychological Review, 103(1), 5-33.

Brown, R. P., \& Zeigler-Hill, V. (2004). Narcissism and the non-equivalence of self-esteem measures: A matter of dominance? Journal of Research in Personality, 38(6), 585592. doi:10.1016/j.jrp.2003.11.002

Buss, A. H., \& Durkee, A. (1957). An inventory for assessing different kinds of hostility. Journal of Consulting and Clinical Psychology, 21(4), 343-349. doi:10.1037/h0046900

Buss, A. H., \& Perry, M. (1992). The aggression questionnaire. Journal of Personality and Social Psychology, 63(3), 452-459. 
Cale, E. M., \& Lilienfeld, S. O. (2006). Psychopathy factors and risk for aggressive behavior: A test of the "threatened egotism" hypothesis. Law and Human Behavior, 30(1), 5174. doi:10.1007/s10979-006-9004-5

Dadds, M. R., Fraser, J., Frost, A., \& Hawes, D. J. (2005). Disentangling the underlying dimensions of psychopathy and conduct problems in childhood: A community study. Journal of Consulting and Clinical Psychology, 73(3), 400410. doi:10.1037/0022-006X.73.3.400

Erikson, E. (1968). Youth: Identity and crisis. New York: W. W. Norton.

Espelage, D. L., Holt, M. K., \& Henkel, R. R. (2003). Examination of peer-group contextual effects on aggression during early adolescence. Child Development, 74(1), 205220. doi:10.1111/1467-8624.00531

Fanti, K. A., Demetriou, A. G., \& Hawa, V. V. (2009). A longitudinal study of cyberbullying: Examining risk and protective factors. European Journal of Developmental Psychology, 9(2), 168-181. doi:10.1080/17405629.2011.64 3169

Frick, P. J. (2003). The inventory of callous-unemotional traits (Unpublished rating scale). New Orleans, LA: The University of New Orleans.

Frick, P. J., \& Dickens, C. (2006). Current perspectives on conduct disorder. Current Psychiatry Reports, 8(1), 59-72. doi:10.1007/s11920-006-0082-3

Frick, P. J., \& Hare, R. (2001). Antisocial Process Screening Device (APSD). Toronto, Canada: Multi-Health Systems.

Frick, P. J., Stickle, T. R., Dandreaux, D. M., Farrell, J. M., \& Kimonis, E. R. (2005). Callous-unemotional traits in predicting the severity and stability of conduct problems and delinquency. Journal of Abnormal Child Psychology, 33(4), 471-487. doi:10.1007/s10648-005-5728-9

Frick, P. J., \& Viding, E. (2009). Antisocial behavior from a developmental psychopathology perspective. Development and Psychopathology, 21(4), 1111-1131. doi:10.1017/ S0954579409990071

Frick, P. J., \& White, S. F. (2008). Research review: The importance of callous unemotional traits for developmental models of aggressive and antisocial behavior. Journal of Child Psychology and Psychiatry, 49(4), 359-375. doi:10.1111/ j.1469-7610.2007.01862.x

Hare, R. D. (1991). The Hare Psychopathy Checklist-Revised $(P C L-R)$. Toronto, Canada: Multi-Health Systems.

Hart, W., Richardson, K., \& Breeden, C. J. (2019). An interactive model of narcissism, self-esteem, and provocation extent on aggression. Personality and Individual Differences, 145, 112118. doi:10.1016/j.paid.2019.03.032

Kawabata, Y., Alink, L. R. A., Tseng, W.-L., Van Ijzendoorn, M. H., \& Crick, N. R. (2011). Maternal and paternal parenting styles associated with relational aggression in children and adolescents: A conceptual analysis and meta-analytic review. Developmental Review, 31(4), 240-278. doi:10.1016/ j.dr.2011.08.001

Kernis, M. H., Cornell, D. P., Sun, C., Berry, A., \& Harlow, T. (1993). There's more to self-esteem than whether it is high or low: The importance of stability of self-esteem. Journal of Personality and Social Psychology, 65, 1190-1204.

Kimonis, E. R., Kennealy, P. J., \& Goulter, N. (2016). Does the self-report inventory of callous-unemotional traits predict recidivism? Psychological Assessment, 28(12), 1616-1624. doi: $10.1037 /$ pas0000292

Kokkinos, C. M., \& Voulgaridou, I. (2017). Links between relational aggression, parenting and personality among adolescents. European Journal of Developmental Psychology, 14(3), 249264.

Myers, E. M., \& Zeigler-Hill, V. (2012). How much do narcissists really like themselves? Using the bogus pipeline procedure to better understand the self-esteem of narcissists. Journal of Research in Personality, 46(1), 102-105. doi:10.1016/ j.jrp.2011.09.006

Okada, R. (2010). The relationship between vulnerable narcissism and aggression in Japanese undergraduate students. Personality and Individual Differences, 49(2), 113-118. doi:10.1016/j.paid.2010.03.017

Öngen, D. E. (2010). Relationships between narcissism and aggression among non-referred Turkish university students. Procedia-social and Behavioral Sciences, 5, 410-415. doi:10. 1016/j.sbspro.2010.07.114

Sng, K. I., Hawes, D. J., Raine, A., Ang, R. P., Ooi, Y. P., \& Fung, D. S. S. (2018). Callous unemotional traits and the relationship between aggressive parenting practices and conduct problems in Singaporean families. Child Abuse of Neglect, 81, 225-234. doi:10.1016/j.chiabu.2018.04.026

Swann, W. B., Stein-Seroussi, A., \& Giesler, R. B. (1992). Why people self-verify. Journal of Personality and Social Psychology, 62(3), 392-401. doi:10.1037/0022-3514.62.3.392

Wang, P.-W., Hsiao, R. C., Chen, L. M., Sung, Y.-H., Hu, H.F., \& Yen, C.-F. (2019). Associations between callousunemotional traits and various types of involvement in school bullying among adolescents in Taiwan. Journal of the Formosan Medical Association, 118(1), 50-56. doi:10.1016/ j.jfma.2018.01.003

Wright, M. F., Harper, B. D., \& Wachs, S. (2019). The associations between cyberbullying and callous-unemotional traits among adolescents: The moderating effect of online disinhibition. Personality and Individual Differences, 140, 41-45. doi:10.1016/j.paid.2018.04.001

Zeigler-Hill, V., \& Besser, A. (2013). A glimpse behind the mask: Facets of narcissism and feelings of self-worth. Journal of 
Personality Assessment, 95(3), 249-260. doi:10.1080/00223 891.2012 .717150

\section{In Korean}

Cha, J., \& Lim, S. (2016). The relationship between self-esteem and aggression among adolescents: The moderating effects of narcissism and self-concept clarity. Studies on Korean Youth, 27(4), 231-258. doi:10.14816/sky.2016.27.4.231

Han, S. C. (2012). Cheongsonyeonhak [청소년학](2nd ed.). Seoul: Hakjisa.

Han, S.-J. (1999). Overt and covert self-relevant cognition of narcissists (Master's thesis). Retrieved from http://www.riss. $\mathrm{kr} / \mathrm{link}$ ?id=T7660473

Hwang, S. T. (1995). Development of diagnostic criteria for personality disorder (Doctoral dissertation). Retrieved from http://www.riss.kr/link?id=T743515

Kim, A. K. (2001). Social behavior in children and early adolescents: Relationships to communication with parents, self-esteem, and depression. Korean Journal of Child Studies, 22(3), 271-285.

Kim, J.-I. (2003). The effect of group art therapy on aggressiveness and impulse for juvenile delinquent (Master's thesis). Retrieved from http://www.riss.kr/link?id=T8985538

Kwon, E., Son, A.-R., \& Hwang, S.-T. (2010). Validation study for inventory of Korea callous-unemotional traits with Korean adolescents. The Korea Journal of Youth Counseling, 18(2), 1-16.

Lee, H.-S., \& Lee, K.-S. (2016). A study on callous-unemotional traits of adolescents with conduct disorder and autism spectrum disorders. Journal of Special Education \& Rehabilitation Science, 55(3), 371-391.
Lim, J. (2012). Relations of proactive and reactive aggression to overt and covert narcissistic features in adolescents at high risk of aggression. Korean Journal of Youth Studies, 19(12), 1-29.

Ministry of Education. (2018). 2018nyeon 1cha hakgyopongnyeok siltaejosa gyeolgwa [2018년 1차 학교폭력 실태조사 결과]. Retrieved from MOE website: https://moe.go.kr

Rho, A. N. (1983). The effects of assertive training on the reduction of aggression and anxiety in juvenile delinquents (Master's thesis). Retrieved from http://www.riss.kr/link?id=T128018

Shim, N. Y., \& Lee, S. Y. (2018). The moderating effects of callousunemotional traits between adolescents' ADHD symptoms and cyberbullying perpetration. Korean Journal of Child Studies, 4O(1), 1-11. doi:10.5723/kjcs.2019.40.1.1

Song, B., \& Lee, J.-Y. (2014). The effects of callous-unemotional traits and narcissistic personality on delinquency of adolescents on probation across gender. The Korean Journal of Clinical Psychology, 33(3), 633-660.

Statistics Korea. (2019). 2019 youth statistics. Retrieved from http:// kostat.go.kr

\section{ORCID}

Sae-Young Han http://orcid.org/0000-0001-8207-5927

Yeon Soo Cho http://orcid.org/0000-0002-8086-644X

Received May 3, 2019

Revision received June 15, 2019

Accepted July 5, 2019 